\title{
Application of Fuzzy Logic to the Speed Control of DC Motor
}

\author{
Gafari A. Adepoju ${ }^{\# 1}$, Ismail A. Adeyemi ${ }^{\# 1}$, Oluwadolapo S. Oni ${ }^{* 2}$ \\ \#,* Department of Electronic and Electrical Engineering \\ Ladoke Akintola University of Technology \\ Ogbomoso, Nigeria
}

\begin{abstract}
This paper presents the application of fuzzy logic to the speed control of DC motor as a way of overcoming the shortcomings of conventional controllers. One of the advantages of fuzzy logic control is that it can be successfully applied to control nonlinear and complex systems using an operator experience or control engineering knowledge without any mathematical model of the plant. A model of separately excited dc motor was created together with the Fuzzy Logic Controller (FLC) using a technical computing software (MATLAB/SIMULINK). The performance of the fuzzy logic controller was studied extensively by simulation to validate the theoretical concept. The simulation study indicates clearly the excellent performance of FLC, because it is adaptive in nature.
\end{abstract}

Keywords - DC motor, speed control, fuzzy logic

\section{INTRODUCTION}

DC motors possess several advantages such as high reliability, flexibility, and low cost over their AC counterparts. These advantages accounts for their wide use in industrial applications such as steel rolling mills, electric trains, electric vehicles, electric cranes, and robotic manipulators where speed and position control of motors are demanded [1]. Conventional controllers i.e. Proportional-Integral-Derivative (PID) controllers, have been applied to control the speed of DC motors. One of the major reasons for the popularity of PID controllers is their simple structure. PID controllers are based on the relatively simple concepts of multiplication, integration over time, and rate of change over time. However, the drawbacks of conventional controllers are that they are sensitive to variation in motor parameters and load disturbances. Moreover, a greata difficulty is encountered in tuning PID gains to eliminate and reduce the overshoot and load disturbance.

The pioneering work on fuzzy logic was done by Professor Lofti A. Zadeh of the University of California at Berkeley in 1965. He proposed the fuzzy set theory which led to a new control method called 'fuzzy control'. The work of Zadeh began to gain recognition after Dr. E.H. Mamdani of London University practically applied the concept of fuzzy logic to the automatic control of steam engine in 1974. During the past few decades, Fuzzy Logic has been widely applied in almost all aspects of our society including industrial manufacturing, automatic control, automobile production, banks, hospital, etc. Today, fuzzy logic is still well recognized. Worldwide, thousands of studies are carried out yearly on this field [2], [3]
Fuzzy logic emulates the pattern of human thinking and natural language than the traditional Boolean logic systems because it can handle the concept of partial truth. For instance, answers like "not very satisfied", "quite satisfied" could be given to some questions in certain surveys. Such answers are fuzzy and ambiguous. What exactly is one's degree of satisfaction or dissatisfaction with some services or products for those surveys? This vagueness is what fuzzy logic helps to overcome. The basic idea of fuzzy systems is that truth values (in fuzzy logic) or membership values (in fuzzy sets) are indicated by a value on the range $[0.0,1.0]$, with 0.0 representing absolute Falseness and 1.0 representing absolute Truth. For a process control system, a fuzzy control algorithm combines the intuition and experience of an operator, designer, and researcher. The fuzzy control method works excellently for systems and processes with unknown or ill-defined models and also for systems with uncertain or complex dynamics [3], [4], [5].

Further sections of this paper give a detailed explanation on DC motor modeling and the design of the Fuzzy Logic Controller. The results obtained from various simulation are also shown.

\section{DC Motor Modeling}

A Separately Excited DC motor has independent voltage supplied to the field and armature (rotor) windings in which this type of structure gives advantage of more control over the motor performance. There are two methods that can be used to control the speed of a Separately Excited DC motor. The first method is the field flux control while the second is armature voltage control. The famous method is the armature voltage control which has advantage to retain maximum torque capability and also allows the variation of speed below rated value. As such, the armature voltage control is chosen [6].

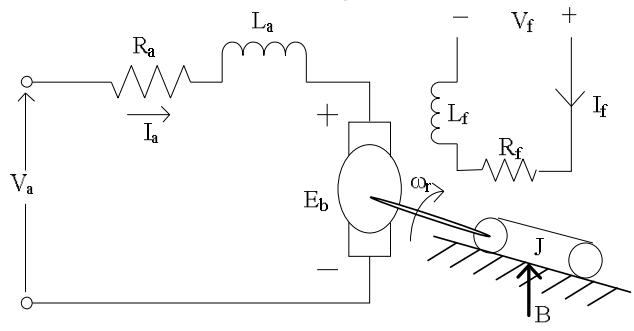

Fig. 1 Model of a separately excited DC motor 
The resistance of the field winding and inductance of the motor used in this study are represented by $R_{a}$ and $L_{a}$ respectively in dynamic model. Armature reaction effects are ignored in the description of the motor. This negligence is justifiable to minimize the effects of armature reaction since the motor used has either interpoles or compensating winding. A fixed voltage $V_{f}$ is applied to the field and the field current settles down to a constant value. A linear model of a simple DC motor consists of a mechanical equation and electrical equation as determined in the following equations. By referring to the armature circuit in figure 1 , the armature dynamics can be derived.

$$
V_{a}(t)=E_{b}+I_{a} R_{a}+L_{a} \frac{d I_{a}}{d t}
$$

Laplace transform of both sides:

$$
\begin{aligned}
& V_{a}(S)=I_{a}(S) R_{a}+L_{a}(S) I_{a}(S)+E_{b}(S) \\
& \frac{I_{a}(S)}{\left[V_{a}(S)-E_{b}(S)\right]}=\frac{1}{\left[R_{a}+L_{a} S\right]}
\end{aligned}
$$

Laplace transform of both sides:

$\mathrm{V}_{\mathrm{a}}(\mathrm{S})=\mathrm{I}_{\mathrm{a}}(\mathrm{S}) \mathrm{Ra}+\mathrm{L}_{\mathrm{a}} \mathrm{SI}_{\mathrm{a}}(\mathrm{S})+\mathrm{E}_{\mathrm{b}}(\mathrm{S})$

$\mathrm{I}_{\mathrm{a}}(\mathrm{S}) /\left[\mathrm{V}_{\mathrm{a}}(\mathrm{S})-\mathrm{E}_{\mathrm{b}}(\mathrm{S})\right]=1 /\left[\mathrm{R}_{\mathrm{a}}+\mathrm{L}_{\mathrm{a}} \mathrm{S}\right]$

According to the Newton's $3^{\text {rd }}$ law, for every applied torque, there are equal and opposite reaction torques. Therefore, differential equation for the mechanical system can be derived:

$\mathrm{T}_{\mathrm{e}}(\mathrm{t})=\mathrm{J} \mathrm{d} \omega_{r} / \mathrm{dt}+\mathrm{B} \omega_{\mathrm{r}}+\mathrm{T}_{\mathrm{L}}(\mathrm{t})$

Laplace transform of both sides:

$\mathrm{T}_{\mathrm{e}}(\mathrm{S})=\mathrm{JS} \omega_{\mathrm{r}}(\mathrm{S})+\mathrm{B} \omega_{\mathrm{r}}(\mathrm{S})+\mathrm{T}_{\mathrm{L}}(\mathrm{S})$

$\omega_{\mathrm{r}}(\mathrm{S}) /\left[\mathrm{T}_{\mathrm{e}}(\mathrm{S})-\mathrm{T}_{\mathrm{L}}(\mathrm{S})\right]=1 /[\mathrm{JS}+\mathrm{B}]$

Motor back emf is proportional to the rotor speed: $\mathrm{E}_{\mathrm{b}}=\mathrm{K}_{\mathrm{E}}$ * $\omega_{\mathrm{r}}$

Motor torque is proportional to the armature current: $\mathrm{T}_{\mathrm{e}}=\mathrm{K}_{\mathrm{T}}$ * $\omega_{\mathrm{r}}$

Where:

$\omega_{\mathrm{r}}$ : motor speed; $\mathrm{J}\left(\mathrm{kg}^{*} \mathrm{~m}^{2}\right)$ : moment of inertia of the whole rotating system, including machine rotor, load couplings, and shaft; $\mathrm{B}$ : viscous friction of motor; $\mathrm{T}_{\mathrm{e}}$ : electromagnetic torque; $\mathrm{T}_{\mathrm{L}}$ : load torque; $\mathrm{K}_{\mathrm{T}}$ : the motor torque constant motor; $\mathrm{K}_{\mathrm{E}}$ Back E.M.F constant.

Table 1 presents the separately excited DC motor characteristics. Mathematical model described through equations (1) to (8) were implemented using MATLAB/SIMULINK software. The SIMULINK model of the separately excited DC motor is shown in figure 2.
TABLE I

DC MOTOR PARAMETERS

\begin{tabular}{|c|c|}
\hline Parameter Name & Value \\
\hline Armature resistance $\left(\mathrm{R}_{\mathrm{a}}\right)$ & $0.5 \Omega$ \\
\hline Armature inductance $\left(\mathrm{L}_{\mathrm{a}}\right)$ & $0.02 \mathrm{H}$ \\
\hline Rated Armature voltage $\left(\mathrm{V}_{\mathrm{a}}\right)$ & $200 \mathrm{~V}$ \\
\hline Rotational inertia $\left(\mathrm{J}_{\mathrm{m}}\right)$ & $0.1 \mathrm{Kg} \cdot \mathrm{m}^{2}$ \\
\hline Viscous friction $\left(\mathrm{B}_{\mathrm{m}}\right)$ & $0.008 \mathrm{~N} \cdot \mathrm{m} / \mathrm{rad} / \mathrm{sec}$ \\
\hline Rated speed $\left(\omega_{\mathrm{r}}\right)$ & $1500 \mathrm{rpm}$ \\
\hline Motor torque constant & $0.5 \mathrm{~N} \cdot \mathrm{m} / \mathrm{A}$ \\
\hline Back emf constant $(\mathrm{k})$ & $1.25 \mathrm{~V} / \mathrm{rad} / \mathrm{sec}$ \\
\hline
\end{tabular}

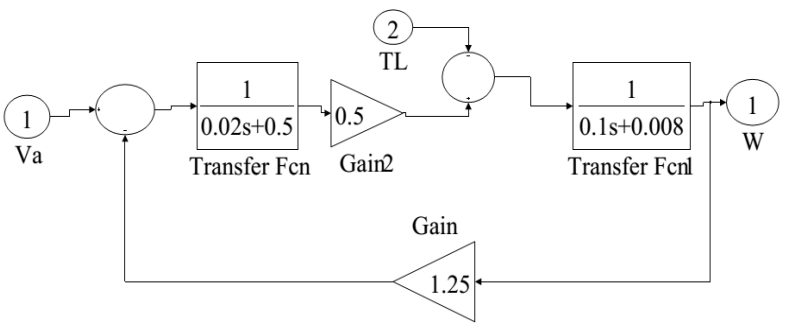

Fig. 2 SIMULINK model of Separately Excited DC motor

\section{FuZZY LOGIC CONTROLLER (FLC) DESIGN}

A fuzzy logic controller has four main components as shown in Figure 3. These components include: Fuzzification, Rule base, Inference operation, and Defuzzification.

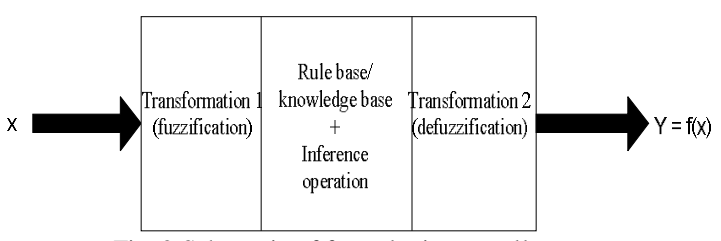

Fig. 2 Schematic of fuzzy logic controller

\section{A. Fuzzification}

The first step in designing a fuzzy controller is to decide which state variables representing the system dynamic performance must be taken as the input signal to the controller. Fuzzy logic uses linguistic variables such as low, medium, high, big, small, positive, negative, zero, etc. instead of numerical variables. The process of converting a numerical variable (real number or crisp variables) into a linguistic variable (fuzzy number) is called fuzzification. The likely values that a variable can assume are named universe of discourse, and the fuzzy sets which are characterized by membership functions) cover the whole universe of discourse. The fuzzy sets can take different shapes such as triangular, trapezoidal, Gaussian, etc. [4].

\section{B. Rule Base}

The rules are in "If Then" format and formally the "If" side is called the conditions and the "Then" side is called the conclusion. The computer is able to execute the rules and 
compute a control signal depending on the measured inputs error (e) and change in error (de). In a rule based controller the control strategy is stored in a more or less natural language.

\section{Inference Operation}

The inference operation comprises an information processing system (such as a computer program) that systematically employs inference steps similar to that of a human brain. It evaluates the fuzzy rules and produce an output for each rule. There are different types of inference engines, e.g. the one using the max-min method, the max-dot product, etc. [7].

\section{Defuzzification}

The reverse of Fuzzification is called Defuzzification. The use of Fuzzy Logic Controller (FLC) produces required output in a linguistic variable (fuzzy number). According to real world requirements, the linguistic variables have to be transformed to crisp output [3], [8]. There are many defuzzification methods but the most common methods are as follows: Center of gravity (COG); Bisector of area (BOA); Mean of maximum (MOM)

Although the conventional controllers depend on the accuracy of the system model and parameters, FLC uses different strategies for motor speed control. FLC process is based on experiences and Linguistic definitions instead of system model. It is not required to know exact system model to design FLC. In addition to this, if there is not enough knowledge about control process, FLC may not give satisfactory results. The goal of designed FLC in this study is to minimize speed error. The bigger speed error the bigger controller input is expected. The change of error plays an important role to define controller input. Consequently, FLC uses error (e) and change of error (ce) for linguistic variables which are generated from the control rules.

A fuzzy rule or knowledge base is in the form of two dimensional table, which can be looked up by the fuzzy reasoning mechanism. Speed error is calculated with comparison between reference speed and speed sigi feedback. Speed error and speed error changing are fuz controller inputs. Input variables are normalized with a ran of membership functions specified and the normalizati factors are named as $\mathrm{K} 1$ and $\mathrm{K} 3$. Suitable normalization $\mathrm{r}$ direct influence in algorithm optimality and faster respon Figure 4 shows the SIMULINK model of separately excit DC motor together with the FLC.

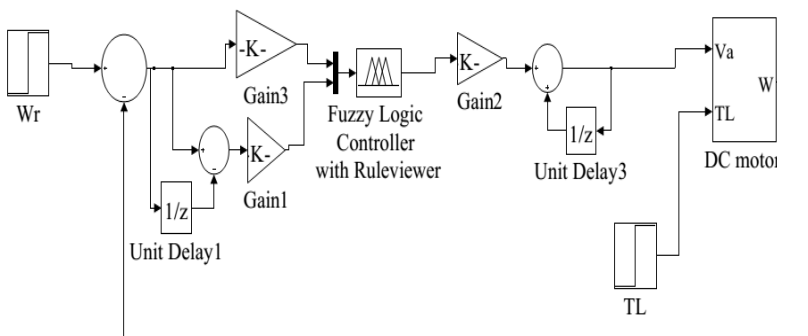

Fig. 4 SIMULINK model of separately excited DC motor together with fuzzy logic controller

TABLE II

THE RULE DATABASE

\begin{tabular}{|c|c|c|c|c|c|c|c|}
\hline $\begin{array}{c}\text { CE } \\
\mathbf{E}\end{array}$ & NL & NM & NS & Z & PS & PM & PL \\
\hline NL & PL & PL & PL & PL & NM & Z & Z \\
\hline NM & PL & PL & PL & PM & PS & Z & Z \\
\hline NS & PL & PM & PS & PS & PS & Z & Z \\
\hline$Z$ & PL & PM & PS & Z & NS & NM & NL \\
\hline PS & $Z$ & $Z$ & NM & NS & NS & NM & NL \\
\hline PM & $Z$ & $Z$ & NS & NM & NL & NL & NL \\
\hline PL & $Z$ & $Z$ & NM & NL & NL & NL & NL \\
\hline
\end{tabular}

\section{Performance Evaluation of The Overall Control SYSTEM}

In this section, the results realized from four different simulations made on the system in figure 4 are presented and discussed. It should however be noted that all the simulations performed were without alteration on the FLC. The first simulation was done with no load applied to the DC motor while the second simulation was done to show the reaction of the control system to load disturbance. The third and fourth simulations were done in order to test the robustness of the controller i.e. the effect of parameters uncertainties on the performance of the controller. The system was simulated with different values of the parameter considered and compared to nominal value (real value). Two cases were considered: moment of inertia $( \pm 50 \%)$; armature resistance $( \pm 50 \%)$. All the simulations were performed for a duration of $20 \mathrm{sec}$ with a speed step of $150 \mathrm{rad} / \mathrm{sec}$.

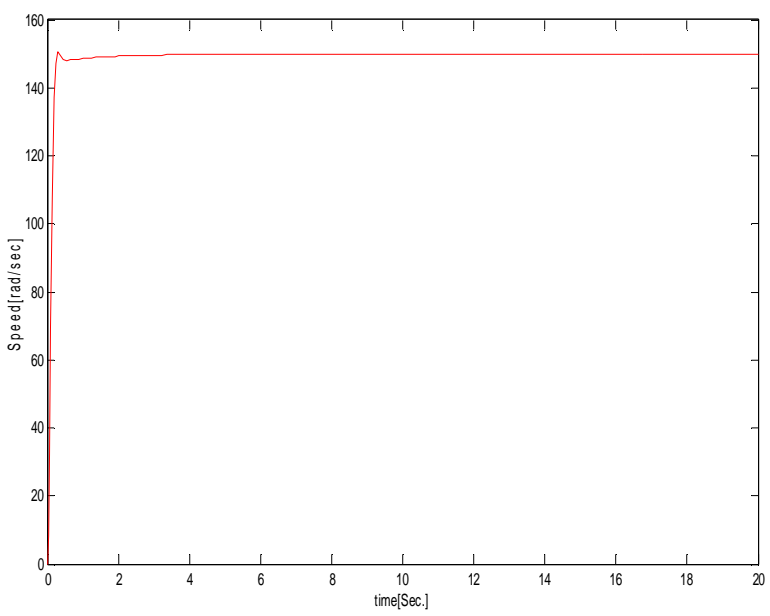

Fig. 5 Angular speed of DC motor based on simulation with no load 


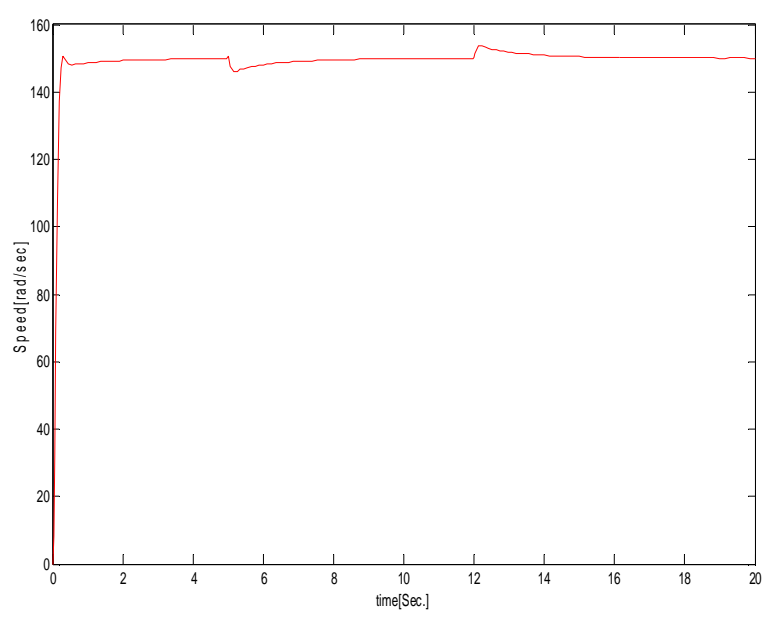

Fig.6 Angular speed of DC motor based on simulation with load

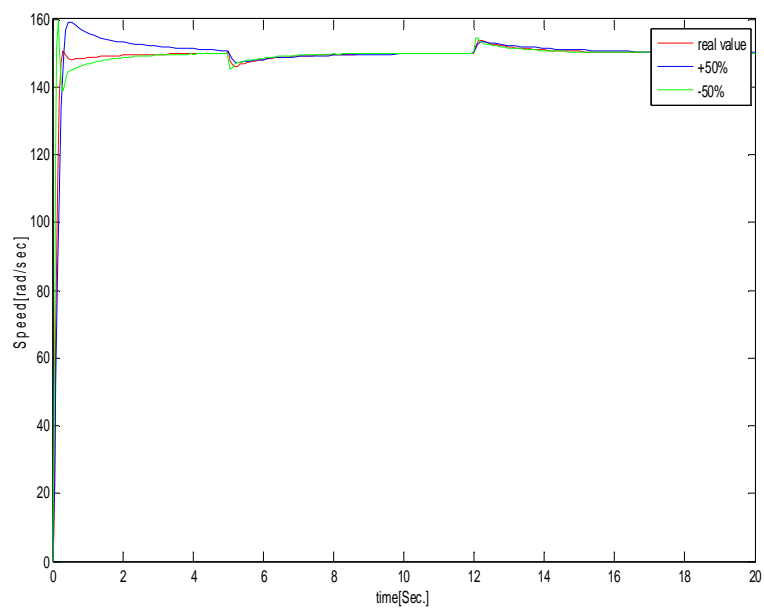

Fig.7 Angular speed of DC motor based on simulation with change in moment of Inertia $( \pm 50 \%)$

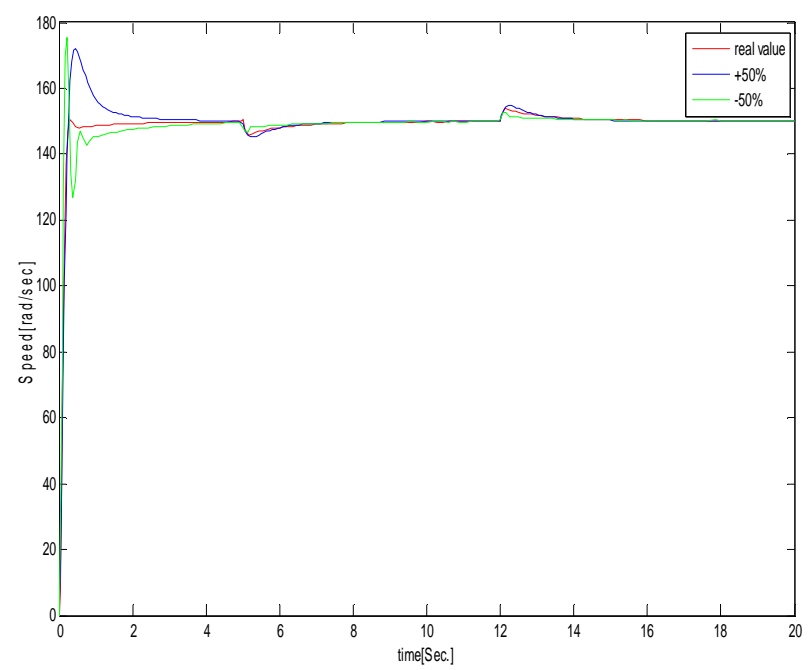

Fig.8 Angular speed of DC motor based on simulation with change in armature resistance $( \pm 50 \%)$
From figure 1, it can be seen that FLC provides good response in achieving the desired trajectory, with no overshoot and a negligible steady state error. Figure 2 shows the quick and excellent reaction of the controller to load disturbances. A load $\left(\mathrm{T}_{\mathrm{L}}=5 \mathrm{~N} . \mathrm{m}\right)$ was applied to the DC motor at $\mathrm{t}_{1}=5 \mathrm{sec}$ and removed at $t_{2}=12 \mathrm{sec}$. With FLC, the effects of load disturbances on the system were minimal. Figure 3 and 4 show the responses of the controller in the presence of variation of parameters considered (moment of inertia; armature resistance). A load $\left(\mathrm{T}_{\mathrm{L}}=5 \mathrm{~N} . \mathrm{m}\right)$ was applied to the DC motor at $\mathrm{t}_{1}=5 \mathrm{sec}$ and removed at $\mathrm{t}_{2}=12 \mathrm{sec}$. From the two figures $(3 \& 4)$, it can be observed that a decrease or increase of the moment of inertia or armature resistance poses no problem to the performance of the controller. The robust nature of FLC gives it a place in the control of systems with uncertain parameters.

\section{CONCLuSion AND Future Research}

This work describes an application of fuzzy logic system to the control of electrical machines. The fuzzy logic control presents a new approach to robust control. The control methodology is described and used to develop a simple robust controller to deal with uncertain parameters and external disturbances. The design of the FLC depends on the structure adopted in fuzzification, defuzzification and rule base. In this work, a complete fuzzy logic control, based on separately excited DC motor, has been described. The system was analyzed and designed. The performances were studied extensively by simulation to validate the theoretical concept. To avoid the complexity of the FLC and the decrease of its precision, seven subsets were adopted to describe each input and output variables. It appears from the response properties that it has a high performance in presence of the uncertain plant parameters and load disturbances. The results of this work show that the control of speed by FLC gives fast dynamic response with minimal overshoot and negligible steady-state error. In future works, the combination of fuzzy logic and other Artificial Intelligence (AI) techniques such as Genetic Algorithm (GA), Particle Swarm Optimization (PSO) etc. could be performed for optimization.

\section{ACKNOWLEDGMENT}

The authors would like to pay sincere gratitude to God, their beloved family, and those who had in one way or the other supported the preparation of this paper.

\section{REFERENCES}

[1] W.I. Hameed and K.A. Mohamad, "Speed Control of Separately Excited DC Motor using Fuzzy Neural Model Reference Controller", International Journal of Instrumentation and Control Systems (IJICS), vol. 2, No.4, Oct. 2012.

[2] A. Kentli, "Studies on Fuzzy Logic Control of Electrical Machines in Turkish Universities: An Overview", Mathematical and Computational Applications, vol.16, No.1, pp. 236-247, 2011.

[3] Bai, Y., Zhuang, H., Wang, D., "Advanced Fuzzy Logic Technologies in Industrial Applications". Springer Publications, 2006. Available at: http://www.springer.com/978-1-84628-468-7

[4] A.G. Aissaoui and A. Tahour (2012). Application of Fuzzy Logic in Control of Electrical Machines, Fuzzy Logic - Controls, Concepts, Theories and Applications, Prof. Elmer Dadios (Ed.), ISBN: 978-95351-0396-7, InTech, Available from: 
http://www.intechopen.com/books/fuzzy-logic-controls-conceptstheories-andapplications/-application-of-fuzzy-logic-in-control-ofelectrical-machines

[5] R. Gayakwad, "Optimized Fuzzy Logic for Motion Control”, Acta Polytechnica Hungarica. Vol.7, No.5, 2010.

[6] Isaac, A. and Victor, S., "Mathematical Modeling and Computer Simulation of a Separately Excited DC Motor with Independent Armature/field control". In proc. IEEE. Ind. Electron. vol. 37

[7] P. Vas (2001). "Artificial Intelligence Based Drives". In: M.H. Rashid. Power Electronics Handbook. Canada: Academic Press.

[8] A. Rubaai (2001). "Fuzzy Logic in Electric Drives". In: M.H. Rashid. Power Electronics Handbook. Canada: Academic Press.

[9] M.S. Krishna and S.S. Narayana, "Design and Analysis of PI like Fuzzy Logic Controlled Buck Converter", International Journal of Electronics and Computer Science Engineering. Available at: http://www.ijecse.org

[10] M. Namazov and O. Basturk, "DC Motor Position Control using Proportional-Derivative Controllers with different Defuzzification Methods", Turkish Journal of Fuzzy Systems, vol.1, No.1, pp.36-54, 2010.

[11] R. Arulmozhiyal and K. Baskaran, "Speed Control of Induction Motor using Fuzzy PI and Optimized Using GA", International Journal of Recent Trends in Engineering, vol.2, No.5, 2009.

[12] G.A. Adepoju, D.O. Aborisade, and O.T. Eluwole, "Speed Forecast of DC Motor Using Artificial Neural Network", International Journal of Applied Science and Technology, vol.1, No.6, 2011. 